\title{
The Organization-as-Iceberg as a Counter-Metaphor
}

Richard Badham, Todd Bridgman and Stephen Cummings

\section{Introduction}

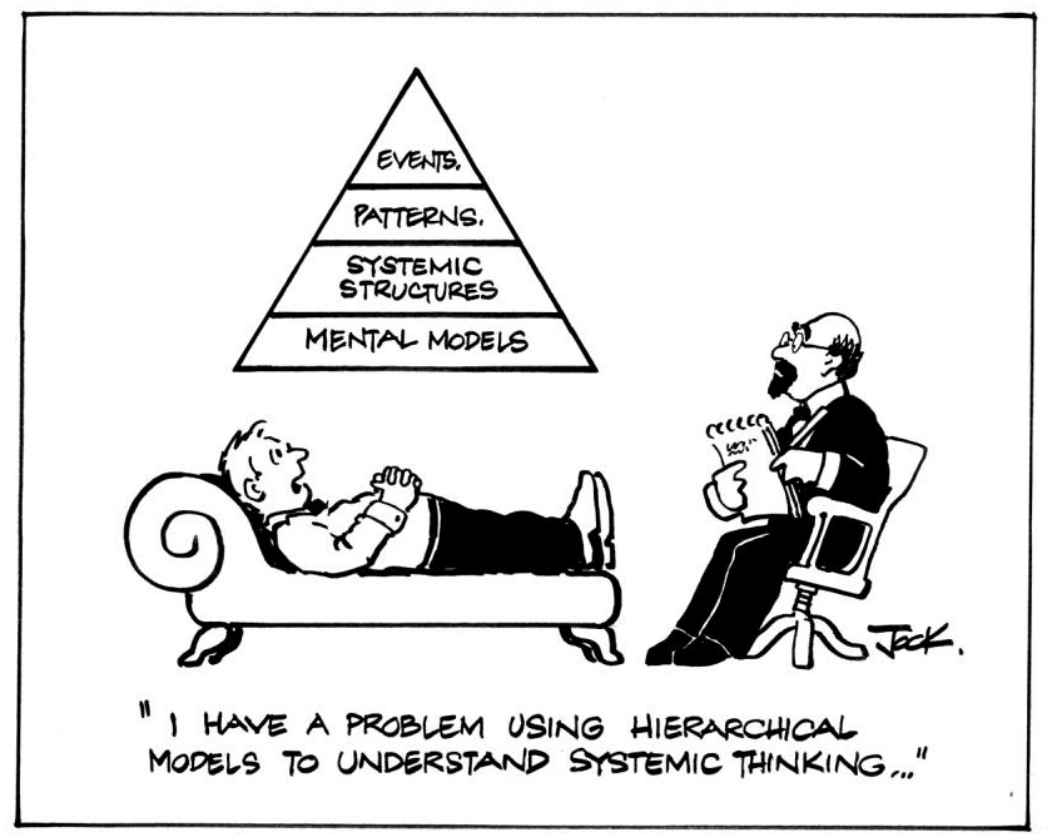

Reproduced with permission from Jock Macneish

Within organization studies, the iceberg metaphor has become what Lakoff and Turner (1989) describe as an entrenched or unconsciously conventional metaphor. We argue, however, it is far from 'dead'. Appearances of the metaphor as a tired cliché can be deceptive. Announcements of its death are greatly exaggerated and, we will argue, unfortunate. Adopting a more dynamic approach to metaphors (Mueller, 2008), we represent the iceberg image as part-dead and part-alive. We make the case for turning it from a 'sleeping' (low activation) metaphor to one that is 'waking' (high activation). We argue further for its refinement and employment as a 'generative' metaphor. In line with Donald Schon (1979), this is an argument for its use as a creative and reflective 'projective model'. We then advocate exploring its value as a generative counter-metaphor to (overly) rational model of organizations (Barrett and Cooperrider, 1990). Conservative or protective uses of 
the iceberg metaphor work within the confines of the rational systems metaphor, advocating a re-engineering of its informal component. Unreflexive adherents to an alternative fluid/process perspective dismiss the iceberg image without examining the ways of seeing and non-seeing embodied in both metaphors. In contrast, we argue for adopting and extending its reflexive and self-critical use as a counter-metaphor. In so doing, this chapter takes a novel approach to historical organization studies. It provides a critical analysis of the genesis, history and evolution of a familiar metaphor as support for its continued relevance and reflexive use in the present.

\section{Iceberg as Sleeping Metaphor}

"try thinking about the corporate culture as an iceberg. Recognize that what you see on the surface is based on a much deeper reality. Recognize that the visible elements of the culture may be sustained by all kinds of hidden values, beliefs, ideologies and assumptions questioned and unquestioned, conscious and unconscious. As a manager, recognize that it may not be possible to change the surface without changing what lies below." Morgan, G. (1989), Creative Organization Theory, pp.157-8

\section{The Standard Narrative}

Ever since the 1970s, the organization-as-iceberg metaphor has remained a staple diet in management education. It has been widely deployed within studies of organizational development (French and Bell, 1973, 1978), organizational culture (Knights and Willmott, 2006), organizational systems (Monat and Gannon, 2015), organizational change (Senior and Swailes, 2016) and organizational accidents (Sun, Paez, Lee, Salem, and Daraiseh, 2006; Swuste, Gulijk, and Zwaard, 2010). Its prevalence is well-established within management student textbooks (Hellriegel and Slocum, 2010; Knights and Willmott, 2006; Mullins and Christy, 2010; Senior and Swailes, 2016), management consultancy rhetoric and practice (Rick, 2014, 2015), linguistic and cross-cultural introductions to the 'dual 
iceberg' (Collier, 2013; Cummins, 2001) as well as practitioner simplifications for disseminating complex system thinking (Kim, 1999). It has recently resurfaced in 'Theory U' approaches to organizational learning and development (Scharmer and Kaufer, 2013).

In most popular introductions to organizational behaviour (Hellriegel and Slocum, 2011: 479-80; Mullins and Chrysty, 2010: 4-9), and similarly popular introductions to change management (Senior and Fleming, 2006: 138/139), the iceberg figures prominently as a means of re-focusing attention onto: 'covert, behavioural' as well as the 'overt, formal' dimension of organizations; the powerful impact the former elements have; the dangers of failing to understand and attend to their consequences, as they are 'often hidden and resistant to change' (Hellriegel and Slocum, 2011: 479); and the difficulties in detection given that the characteristics are 'mainly hidden', 'rarely talked about' and one has to 'guess' at how large it is and its significance. In popular parlance the implication of the iceberg metaphor is to highlight the 'hidden' nature of the tacit, informal and covert dimensions of organizational life, and the 'dangerous' consequences of a failure to appreciate its depth and significance. As Senior and Fleming (2006: 139) note, the 'difficulties in detecting the extent and characteristics of the hidden part of the iceberg are analogous to the difficulties encountered in examining and understanding the more informal, hidden aspects of organizational behaviour' and, as Mullins and Chrysty (2010: 4) remark, citing Hellriegel, Slocum and Woodman (1998: 5), 'What sinks ships isn’t always what sailors can see, but what they can't see.' Rick $(2014 ; 2015)$ reinforces the Titanic icon, in warning that seemingly well-planned and structured 'unsinkable' change interventions often founder after 'collision' with the less visible and not considered bulk of the organization that lies beneath the surface. 


\section{A More Complex Story}

Beneath this surface view, however, lies a more complex picture. It is a picture that makes the iceberg metaphor more interesting and its use more complex and problematic.

\section{The Nature of its Content}

From an historical standpoint, the nature and origins of the metaphor are shrouded in ambiguity and misrepresentation. Its origins are regularly attributed to the anthropologist Edward Hall in his book Beyond Culture (1976), drawing on his work from the 1950s, yet there is no mention of the iceberg metaphor in that book (see discussion in Chiarra, 2019)! Moreover, Hall's brief reference to the metaphor, was in another and earlier book Silent Language (1959: 86) and it was to critique the concept. In Hall's words, while the 'iceberg analogy was commonly used when teaching this theory [levels of culture] to students and laymen alike', 'it soon turned out this theory was inadequate.' The iceberg metaphor in organizational development was popularised by Wendell French and Cecil Bell (1973) as a two-level image focused on culture. Yet Stan Herman, the attributed author of the metaphor, employed a three-level image with a stronger focus on the importance of power and influence (Herman, 1971, 2018). The organization as culture image is frequently attributed to Edgar Schein (Knights and Willmott, 2006), yet Schein never used the term iceberg, and is critical of it (Schein in Brighton, 2015). As he recently notes, "I did not like it because the basic assumptions that I consider the DNA of culture are neither so huge nor so static' (Schein, 2020).

Similarly, some attribute the origins of the iceberg metaphor in organizational learning and system dynamics to the work of Peter Senge in The Fifth Discipline. Yet Senge made no mention of it. The precise origins of the metaphor are unclear (Cavana, Goodman, and Maani, 2018; E. Cunliff and Monat, 2018) and many systems thinkers are critical of its over- 
simplification (Cunliff in Cunliff and Monat, 2018; Hitchins, 2018). Images of the iceberg

within this literature also vary considerably in terms of number of levels, what lies above and below the 'surface', and whether the iceberg refers to levels of causation or perspective (Cunliff, 2008). Finally, within organizational health and safety, the iceberg metaphor is often attributed to the German safety scholar Heinrich in his writings in 1927-9. Yet he, also, never used the term, and the nature of the iceberg metaphor shifts over time in critical discussions of alternative views of causes and costs of injuries and accidents (Swuste, 2018; Swuste et al., 2010). Each of these literatures rarely, if ever, refer to the others.

Part of the current 'sleeping' nature of the iceberg metaphor is the uncritical acceptance of its overly simplified and inaccurate history. This chapter provides a more considered and reflective account in the belief that this may help to re-energise discussion and improve the use of the metaphor in three ways.

Firstly, by acknowledging the ambivalent support given to the image from the outset. As Hall, its early critic notes, its use of somewhat misleading and overly-simplistic bipolar categories also made it accessible to traditional mindsets, allowed the making of important distinctions and raised important issues around what it was and was not possible to talk about (Hall, 1959, 1966, 1976).

Secondly, by encouraging an appreciation of its openness and ambiguity as contributing to it's generative content and employment. Consideration of the historically diverse views of what lies above and below the 'waterline', and where to draw that line and its significance, opens up such issues for valuable discussion. 
Finally, by highlighting historical and current sensitivity to the limitations of the image. This can be used to support a reflective and creative discussion of its nature and role as both a 'way of seeing' and 'way of not seeing'.

\section{The Significance of its Context}

Attention to the context of the iceberg's resonance and use is also of significance in exploring the appeal it has, the opposition it generates and its future use.

Its popularisation in the 1970s was in an era of 'systems rationalism' (Barley and Kunda, 2010). This underlay support for its capacity to shift discussion of individual and group level characteristics and developments and onto organization-wide phenomenon, and to do so with an eye on systematic characteristics and scientific diagnosis. This was also an era marked by greater awareness of the limitations of overly rational views of individuals and organizations, and the importance of sensemaking and politics in enacting organizational realities (Burns, 1961; Cohen, March, and Olsen, 1972; Colville, Brown, and Pye, 2012; Dalton, 2017; Meyer and Rowan, 1977; Weick, [1969] 1979). Finally, this period was characterized by multiple critiques of organizational life, from the emptiness of the corporate gamesman (Maccoby, 1978) and the rising culture of narcissism (Lasch, 1979) to the limitations of organization man (Whyte, 1956) and the dysfunctionalities of emotional labour (Hochschild, 1983). It was also the era of protests against the Vietnam war, corporate imperialism, global inequality and under-development. The iceberg metaphor's pointing to the 'dangers' that lie beneath the surface of organizational life, and the importance of understanding, sympathizing and collaborating with different values and perceptions, resonated with this context. 
In the current era, we have witnessed a variety of constructivist 'turns' in organizational studies, greater recognition of complexity and turbulence, and increased attention to agility and adaptability in fluid and changing conditions. In contrast, the frozen appearance of an iceberg metaphor appears to align it with outdated 'ice cube' models of change (Cummings, Bridgman, and Brown, 2016; Kanter, Stein, and Jick, 1992). Its rigid and object like character appear anachronistic in an era in which it is more popular to highlight fluidity and narrative interpretation (Bennett, 2013a, 2013b; MacQueen, 2020). Moreover, its hierarchical and threatening character appears out of tune with emphases on networks, empowerment, collaboration, appreciative inquiry and generative dialogue (Schein in Brighton, 2015).

At the same time, however, there is widespread awareness that, despite such developments, overly-rational views of individuals and organizations continue to dominate (Brunsson, 2014; Mccabe, 2016; March, 2007; Rowan, 2002). Despite the rhetoric, there is heightened sensitivity to continuing bureaucratic inertia, corporate grandiosity, functional stupidity and 'bullshit', enduring systemic inequalities and discrimination, absence of intelligent, creative and responsible leadership, and widespread organizational silencing and dangers in 'speaking up' (Buchanan and Badham, 2020). The iceberg metaphor simply and directly speaks to such issues through the stark contrast it draws between rational legitimation and formal rhetoric, on the one hand, and the realities of uncertainty, hypocrisy, emotion and power on the other. As we will illustrate below, the iceberg image can act as a clear and simple sensitising concept and useful reminder of the pernicious effect of neglecting such realities, in a way that more refined and esoteric concepts and images fail to do. If the latter is the case, and alternative challenges to over-rational models have so far failed to resonate, then this ambiguous and ambivalent appeal of the iceberg metaphor raises interesting and 
important issues and challenges.

\section{All Quiet on the Metaphor Front}

For a metaphor that is so commonly recognized and widely used in management education, and one that raises a number of interesting and thorny issues, there has been a remarkable absence of any discussion or debate about its significance within organization studies. The metaphor rarely appears in formal academic discussions of the role of metaphors within organizational behaviour and change. (Cornelissen, Oswick, Christensen, and Phillips, 2008; Jacobs and Heracleous, 2006; Maclean, Harvey, and Stringfellow, 2017; Marshak, 1993; Morgan, 2006; Palmer and Dunford, 1996). It is significant that the metaphor is absent from Gareth Morgan's celebrated Images of Organization, although he does deploy it as a creative aid in his summary of tools in Creative Organization Theory (1989). Without explanation, French and Bell (1973) dropped the use of the 'iceberg' metaphor in their third 2008 edition. No reference is made to the iceberg metaphor in contemporary overviews of perspectives on organizational theory (Hatch, 2013; Westwood and Clegg, 2003), organizational culture (Alvesson and Sveningsson, 2016; Giorgi, Lockwood, and Glynn, 2015) and organizational change (Hughes, 2019; Stouten, Rousseau, and De Cremer, 2018). Some popular extensive introductory textbooks on organization behaviour, culture and change, do not include the iceberg (Buchanan and Huczynski, 2019; Burnes, 2017; Hayes, 2020).

In this chapter we attempt to contribute towards addressing this gap, by exploring the potential, issues and challenges involved in 'waking up' this metaphor from its slumber and deploying it as a generative counter-metaphor to (overly) rational models and myths of organizational life. 


\section{Iceberg as Generative Metaphor}

\section{Thatcher: 'The Labour party iceberg manifesto, one tenth of its socialism visible, nine tenths beneath the water (laughter).'}

Kinnock: 'In a way she was right, it's a bit of an iceberg manifesto. It's really cool, and it is ah very tough, and it is totally unsinkable.'

Wilson, J., (2015) Political Discourse, p.780

The iceberg metaphor is inevitably generative. It creates by analogy ('seeing as') a variety of possible 'ways of seeing' and 'ways of not seeing' organizational life. But this generativity can be used in different ways and for different ends. For the purposes of this chapter, we approach this issue of generativity in relation to both the content of metaphor and the context of its use.

\section{Generative Content of the Iceberg Metaphor}

Encouraging the view of organizations as an 'iceberg' re-affirms yet challenges the significance of the rational nature of organizational life. At an immediate level, it points to the existence of a prominent and visible rational 'tip', evident in formal structures, official rhetoric and public displays. Yet it also takes a 'deeper' look at the human dimensions of organization that are ignored, obscured or repressed by this 'surface' view. It combines this bi-polar image with encouragement to go beneath the 'waterline'. It implies that it is important to achieve a greater understanding of what lies 'below' and take this into account in situations when opportunities and threats are missed through being misled by a partial focus on the more obvious 'tip'. Like the popular idiom that emerged in the 1960s, the 'tip of the iceberg', this metaphor highlights that in organizational life 'there is more to this than 
meets the eye'. It also warns us of the 'Titanic'-like effects of ignoring the foundering of organizational initiatives on neglected cultural, political and emotional conditions that lie beneath the organization's rational surface.

The power of the iceberg metaphor lies in its resonance with broader, deeper and highly emotive imagery about modern life and culture. As Black (1993: 26), emphasizes, an active metaphor always requires:

'the receiver's cooperation in perceiving what lies behind the words used, and 'strong' metaphors have a high degree of background resonance and implicative elaboration i.e. how far the 'interpretative response can reach will depend upon the complexity and power of the metaphor-theme in question: Some metaphors, even famous ones, barely lend themselves to implicative elaboration, while others, perhaps less interesting, prove relatively rich in background implications. For want of a better label, I shall call metaphorical utterances that support a high degree of implicative elaboration resonant.

Without such resonance, Black notes, a metaphor is akin to an 'unfunny joke'. The failure of alternative counter-metaphors such as 'garbage can', 'irrational organization', 'wonderland' or 'rhizome' to catch on may be attributable to such a lack of popular resonance.

Four images embedded within significant modern social imaginaries (Taylor, 2004) underlie the strong cultural resonance of the iceberg metaphor. These images are intertwined with, and underlie, common characterisations of the iceberg as highlighting the contrast between the formal and informal in organizational life, the dangers of deeper irrational factors that underlie the veneer of rationality and the Titanic-like hubris that leads to us ignoring such factors.

The first image is what we commonly recognize as a 'double plot' in social life (Gusfield, 2000): on the one hand the socially approved expectations and technical requirements of the roles we play in society; on the other hand, our distance from such roles, the strain of shutting 
off other thoughts and behaviours in order to conform, and consequently our ambivalence towards them. As Burns (1961: 261-2) emphasizes, organizational members are confronted by a 'dual linguistic and moral code' as 'atone and the same time co-operators in a common enterprise and rivals for the material and intangible rewards of successful competition with each other' (see Buchanan and Badham, 2020). The lived experience of our organizational self consequently lies not in official pronouncements of our corporate role but in our responses to them (Kunda, 2006)!

A second image is modern appreciation of the predictable irrationality of human beings (Ariely, 2009). As Aronson (1989: 134) observed, 'Man likes to think of himself as a rational animal. However, it is more true that he is a rationalizing animal, that he attempts to appear reasonable to himself and others" (see Aronson, 2018). As Hall (1959: 83-4) put it, the work of Sigmund Freud marked an important development in our modern conception of human behaviour:

"No longer was man considered to be entirely rational, ruled by logic. No longer could he be conceived of as an elegantly tooled machine run from the higher centres of the brain. Man became much less predictable but much more interesting when he was viewed as a battleground of conflicting drives and emotions, many of them hidden. After Freud it became common to think of man as a being who existed on a number of different levels at once".

While Freud never used a phrase commonly attributed to his work, an 'iceberg theory of the mind' (Green, 2019), his ideas lent themselves to and reinforce such a basic image, with a focus on conscious rationality as the tip and unconscious irrationality below the surface.

A third image combines the latter two in widespread understanding and concern about the 'dark' side of modernity (Alexander, 2013). The idea that there are dangerous depths within the project of modernity, and that this is, in part, both caused and perpetuated by 
'rational' repression is an underlying component of the cultural fault-lines within the modern consciousness (Childs, 2008). While the formal structure and rhetoric of organizations continue to be dominated by the 'rational myth' (Badham, 2017; Brunsson, 2014; Edelman and Talesh, 2011; Mccabe, 2016; Rowan, 2002), equally widespread are competing 'social imaginaries' (Taylor, 2004) or 'orders of worth' (Boltanski and Thevenot, 2006; Jagd, 2011) Not only do these prioritize values other than efficiency and profits (e.g. individualism, freedom, equality, community), they also warn about the dangers of subordinating life to instrumental rationality and institutional hierarchy (Alexander, 2013; Alvesson and Spicer, 2016; Badham and King, 2020).

A fourth image is different to the other three, in the sense that it is tightly linked to a symbolic event. It merits separate consideration because of its powerful mythical illustration of scepticism at modern technological hubris - this is the imagery of the fate of the Titanic. While possibly inaccurate, although not too far from the truth, one historian asserted that the three most written-about subjects of all time are Jesus, the American Civil War and the Titanic. As exemplified in the satirical newspaper headline quoted at the head of the next section, the Titanic (with a name drawn from the classical Greek race of superbeings, the Titans), is a symbol of mankind's hubris (Mendelsohn, 2012). As employed in many introductions to the iceberg in organization behaviour and change, the dangers of underestimating the size and significance of the iceberg are illustrated by the image of the sinking of the Titanic (Rick, 2015).

As a result of its alignment with this background imagery, the organization-as-iceberg metaphor creates a simple, resonant and emotive 'way of seeing' organizations. It acknowledges how we are seduced into noticing and focusing on rational appearances. It 
points to the significance and importance of what we intuitively (as cultural 'moderns') recognize as a more human dimension of organizational life, one that runs counter to the formally rational. Finally, recommendations to 'flip the iceberg' can build on the idea that the rational 'tip' is a small visible part of something larger without being restricted by seeing what 'lies below' as primarily dangerous.

\section{Generative Process for the Iceberg Metaphor}

A generative process for applying the iceberg metaphor uses the metaphor in a creative and reflective manner. One of the most distinctive features of past use of the iceberg metaphor is the absence of any generative process in its use. The term is commonly employed, praised or condemned with little serious or systematic consideration of its multiple uses, diverse implications and the costs or benefits of its reflective use. This gap can be addressed in two ways. Firstly, by drawing on relatively standard views of what is involved in the reflective and generative use of metaphors (Cornelissen et al., 2008; Jacobs and Heracleous, 2006; Palmer and Dunford, 1996). Secondly, by drawing on a more comprehensive and nuanced history of the iceberg metaphor in order to inform such a use. We shall address seven key issues that the generative use of the iceberg metaphor needs to be reflexive about and explore.

\section{Overlap and Difference}

This is the degree to which the similarities and differences between an 'actual' iceberg and an 'actual' organization affect its usefulness as a creative tool. This needs to be sensitive to the fact that this 'overlap' is not objectively given but shaped by views and uses of the iceberg metaphor itself. Icebergs, for example, may be viewed as too fixed and rigid to be a useful 
image of an organization, yet they may also be viewed as relevant as they are more alive and fluid in nature than has been recognized in the past (Wessel, 2018).

\section{Ambiguity and Complexity}

This is the ambiguous, imprecise and complex nature of the iceberg image, something that if ignored may simply confuse thought and action or if deliberately deployed may be valuable as a way of establishing a shared understanding and direction. The iceberg image, embedded in bipolar explicit/implicit views of culture, faces Hall's original challenge: 'Like many other abstractions about culture, this one leaves us with the feeling, "Where do we go from here?" (Hall, 1959: 86). This can be seen as a sign of weakness, and hence the popularity in the 1980s (following the 70s rise in popularity of the iceberg image) of more refined models such as McKinsey’s 7S Model, Johnson and Scholes' Cultural Web, Galbraith's STAR model or Nadler-Tushman's Congruence Model etc. At the same time, however, as Hall points out, the 'bipolar' distinction can be valuable in making new distinctions, enabling us to see behaviour on two levels and resonating with 'American' prejudices for polarized thinking. We might also add that it provides a general orientation for challenging over-rational expectations and views of organization, in ourselves as well as others, without restricting how we follow up this insight by employing any of a variety of models.

\section{Prescription and Description}

This is the interrelation between views of the iceberg as a description of how individuals and organizations view themselves and prescriptions for how they should be viewed (Cornelissen et al., 2008). On the one hand the iceberg metaphor describes an over-preoccupation with the formal, cognitive and rational surface within organizations and their members. On the other hand, it prescribes paying greater attention to the 'bulk' of symbolic, emotive and political 
issues and relations on the advice that it is dangerous to do otherwise. Paying attention to the level to which this image, or its counter, is present in organizations, or the degree to which its insights should be present and attended to is a significant component of its reflective use.

\section{Literal and Figurative Dynamics}

This is the manner and degree to which the iceberg is presented as a sensitizing and motivating image or a more or less accurate description of the realities of organizational life. A focus on the former highlights its usefulness as a stimulus and provocation, while attending to the latter is more concerned with its empirical accuracy and analytic power. Despite preferences of some analysts for one or the other, a reflective view does not treat this as an either/or question.

\section{Insights and Blindness}

These are the ways in which the iceberg metaphor represents a way of seeing and not-seeing. Supporters of the metaphor (Cunliff, 2008) and those who find it useful (Clegg, Kornberger, Pitsis, and Mount, 2019; Mullins and Christy, 2010; Senior and Swailes, 2016) frequently point to its valuable role in highlighting the significance of informal, tacit and non-rational forces in an organization. Its critics emphasize that it is rigid, object like and negative in its portrayal of culture and its impact (Bennett, 2013a; Brighton, 2015; MacQueen, 2020). A creative focus and deployment of the concept addresses these and other potential implications as part of discussions of the relevance of the image.

\section{Opportunities and Challenges in Use}

These are the cultural and political factors that support or oppose the effective deployment of the iceberg metaphor as a means for challenging overly-rational views of organization. On 
the one hand, the iceberg image resonates with routine observations about the existence of formal and informal dimensions to organizational life, its apparent object like character appeals to objectivist prejudices and its unitary character reinforces mechanistic and organic managerial assumptions about organizational goals. It is only reasonable to assume that these elements may contribute to its credibility, and may be highlighted or deployed in the use of the image in an overly rational and unreflective manner. On the other hand, the iceberg metaphor portrays the bulk of organizational issues as not belonging to the rational 'tip', includes feelings, identities and diverse political interests 'inside' the system that is being looked at rather than outside, and these elements can be used to challenge the more traditional and conservative use of the image. Both of these potentials can, and should, be explored, in regard to both the content of the metaphor and its likely or possible contextual uses.

\section{Similarities, Differences and Irony}

These are the differences as well as the similarities between icebergs and organizations. Rather than simply illustrating similarities (e.g. observable surface 'tip', hidden 'depths', 'dangers' of neglecting the 'bulk' beneath etc.), the differences can be highlighted as a basis for disrupting existing perceptions (e.g. are organizations 'frozen' in this way, can we separate 'above and below the surface' issues in a mechanistic way, are cultures and politics potentially enabling and supportive as well as obstructive and dangerous etc.). Alternative elaborations of the iceberg metaphor can also be involved, drawing on more fluid images of the life cycle of icebergs, the life forms they include, the flipping that sometimes occurs, what the world looks like from the perspective of the iceberg rather than those viewing or dealing with it and so on. These can be used as an ironic counter to the ways that it has been 
viewed and deployed in organizations and organization studies. Such reversals are illustrated in the quote at the beginning of this section.

\section{Iceberg as Counter-Metaphor}

'World's largest metaphor hits iceberg - Titanic: Representation of man's hubris, sinks in North Atlantic'.

The Onion (1999)

\section{Countering Metaphors}

The resonance and powerful effect of the iceberg metaphor as counter-metaphor comes from its use of a variety of, admittedly overlapping, methods for countering metaphor (Underhill, 2012) and making counter-claims (Gabriel, 2016) against dominant ideologies and viewpoints.

Countering metaphors can employ a variety of strategies (Eubanks, 2000; Underhill, 2012) including :

- Ascription of metaphors;

- Negating, contrasting or mirroring metaphors; and

- Foregrounding, paradoxical and ironic metaphorical strategies

\section{Ascription}

Ascription involves revealing the metaphor underlying a perspective, thereby opening up contrast, reflection and criticism. The embedded nature of rational systems models means that the use and influence of metonymic elaborations often goes unnoticed, such as 'function', 'role', 'health', 'survival', 'fit', 'alignment', 'heart', 'stomach', 'brain', 'processing', 'oiling', 'wheels', 'cogs', 'nuts and bolts', 'hard-wired', 'software', 'short circuits', and even 'purpose', 'goals' and 'objectives' . The iceberg metaphor 'short-circuits' the use of such terminology in a number of ways. The term is clearly, and often self- 
consciously, a metaphorical image, implicitly highlighting its own role and that of others. Without denying that system assumptions are made, the metaphor relegates the use of associated terms and forms of thought to the superficial. This results from the persuasive part-tacit and part-strategic metonymic elaborations such as the 'tip of the iceberg', the need to go beneath the 'surface' or below the 'waterline', the desirability of 'plumbing the depths', being aware of the 'dangers that lurk below' and so on.

\section{Negating, contrasting and mirroring metaphors}

This involves dismissal, creating alternative contrasting metaphors and inverting or reversing the original. In one sense, the iceberg metaphor can be seen as negating, as it dismisses simple rational systems thinking as ignoring the most important features of organizational life. It also directly counters rational strategic system metaphors by contrasting it with an alternative metaphor that highlights the systemic informal as well as formal dimensions of an organization. As an inversion or reversal, the iceberg performs the above activity by portraying what the rational strategic model ignores to be the 'bulk' of what goes on in organizations as fundamental and primary, and inverts what it takes to be most important to be secondary and less significant.

\section{$\underline{\text { Foregrounding, Paradoxical and Ironic strategies }}$}

Foregrounding involves illuminating some features, and hiding or de-emphasizing others, while paradoxical metaphors highlight the existence of two opposite terms in tension in relation to one image, and irony involves using satire and parody to ridicule the dominant metaphor, through exaggeration, distortion or extension. The iceberg image clearly foregrounds the informal, uncertain, emotive and political dimensions of organizational life at the expense of the formal, certain, cognitive and unitary. It does to such a degree that those 
responsible for developing and using the concept are frequently at pains to emphasize the formal tip still has relevance (Herman, 2018), emphasizing that concentrating on issues below the surface is not to 'ignore or deny the legitimacy' of those above (Herman, 1971: 603). As a paradoxical metaphor, the iceberg challenges the view of organizations as rational systems, yet includes emotions and politics in what could be understood as a broader and more comprehensive system view. As Herman (1971: 602) puts it: 'feelings are indeed facts' and they are 'in the system'. The ironic twist embodied in the iceberg metaphor is exemplified in the Titanic quote at the introduction to this section. The hubris of mankind's (or the organization's) excessive faith in rationality, technology and control is parodied by equating this with a surface and superficial distraction with an immediately obvious tip, while, ironically, only increasing the disastrous likelihood of 'sinking' after collision with what this outlook ignores or denies.

\section{Counter-Troping and Reversing Dominant Tropes}

Within this process, counter-tropes involve creating alternative tropes or reversing the dominant trope, through ridicule or novel elaborations (Steinitz, 2015). In order to reverse a dominant trope, the use of the iceberg metaphor needs to be embedded in a process that Sillince and Golant (2017), developing the insights of Oswick, Keenoy and Grant (2002), describe as 'cycling between irony and metaphor'. In this process, one metaphor is not simply counter-posed to another as an alternative perspective, but used in an overturning or reversal of an established metaphor in order to open up the space for alternatives. Despite such authors pointing to this phenomenon, it has rarely been elaborated in any detail. The most extended analysis is provided by Kenneth Burke in his argument for the rhetorical power of adopting a 'perspective by incongruity' (Burke, 1935; George, 2018). In order to challenge an attitude-laden perspective, Burke argues, it is necessary to get 'buy-in' to an 
alternative. In order to do so, he recommends and outlines a 'corrective' rather than a 'debunking' approach, one that opens up creativity and imagination rather than offering a counter-dogma and set of prescriptions. This process involves verbal 'atom cracking' by challenging dominant perspectives, attitudes and associated metaphors in their own terms, using, converting, twisting and challenging their established 'pieties' and 'prejudices'.

Burke outlines five key dimensions of this process: Identifying the existing 'dramatic vocabulary (e.g. metaphors, images and related attitudes associated with the rational model, and the 'representative anecdotes' that capture them); adopting a 'corrective' orientation towards critique, drawing on or framing any questioning or exposure in terms of the original concepts, images and prejudices (e.g. use of the 'system' model against itself, drawing on popular bi-polar imagery of organizational life); creating a 'jolt' through portraying the ideas and images in the original metaphor in an 'incongruous fashion' (e.g. the neglect, and danger of, ignoring the 'bulk' of the organization beneath the surface); bringing about a 'conversion' through incongruous vocabularies that 'converts downwards' what are held in high esteem or 'converts upwards' what are put down (e.g. the dominant formal structures and rhetoric become a superficial 'tip', while the 'soft' issues become the crucial support and potentially dangerous 'bulk'), or merges categories that are held to be exclusive or divide those that are held to be inclusive (e.g. uncertainty, emotion and politics are included 'within' the organizational system, and rational thought now points to the 'limits' of rationality); and adopting a 'comic frame' that emphasizes the partiality, entrapments, foibles and overinflated expectations and dramas embedded in all perspectives, and the fallibility and folly of those who adhere to them (e.g. using a simple concrete metaphor suggests the partiality of this and other contrasting images, and reminders about the iceberg foster an expectation, appreciation of and adaptation to the irrationalities of organizational life). 


\section{Conclusion}

Understanding the reality of covert culture and accepting it on a gut level comes neither quickly nor easily, and it must be lived rather than read or reasoned. Edward T Hall, (1976), Beyond Culture, p.58

In the 'War is Over, the Victors have Lost' and 'Management and Don Quixote', March notes laconically that despite narrow disciplinary recognition of the limitations of the overlyrational managerial image of organizations, its continuing influence remains in business schools and organizations as its 'justifications and explanations of action have been sanctified, they are accepted as morally and pragmatically obvious, they are taught as sacred dogma' (March, 2007: 1).

If we take seriously the case for developing critical and reflective practice (Reynolds and Vince, 2016, se also Chapter 3 of this volume by Durepos and Vince), practical wisdom (Schwartz and Sharpe, 2011), phronesis (Flyvbjerg, 2001) or metis (Chia and Holt, 2008; Scott, 1999) in management education, this represents a significant challenge. How do we provide an effective embodied metaphor (Jacobs and Heracleous, 2006) to counter a dominant, pervasive, culturally pernicious and institutionally sanctioned rational myth, with its attendant images, metaphors and licencing stories?

So far, alternative metaphors have failed to gain traction. As even their supporters acknowledge, direct counter-metaphors such as 'garbage can', 'irrational organization', 'unmanaged organization' and 'wonderland' have not become strongly integrated into the 
assumptions and practices of strategy, operations, finance and even organizational behaviour (Brunsson, 2014; March, 1992; Mccabe, 2016).

This is our starting point, and rationale for exploring possible counter-metaphors, and the particular case of the iceberg. However, given the tenor of the times, in the first instance, the iceberg metaphor seems uniquely unsuitable for resuscitation. The traditional organizational development 'ice cube' model of change as a process of unfreezing, moving and refreezing has been frequently parodied (Kanter, Stein, and Jick, 1992) and widely condemned (Cummings et al., 2016), and by implication also 'iceberg' imagery. In a more 'processual' era, preferences are frequently expressed for more fluid metaphors. This frequently involves using rivers, tributaries, permanent white water, currents and undercurrents, beaches and waves, as well as imagery of kayaks, surfers and sailing ships. These are designed to help capture the challenges of navigating unpredictable emergence, turbulence and complexity (Badham, 2013; Es, 2011; MacQueen, 2020; Pettigrew, 1979; Schein and Schein, 2019; Vaill, 1989). As these assumptions became more embedded in contemporary discourse, the iceberg metaphor began to look rather like a tired cliché from an early modern era, and worthy of little interest. Given this situation, one may reasonably ask 'why bother to 'waken' a sleeping metaphor like the iceberg?' We believe there are three main reasons.

Firstly, the iceberg metaphor resonates strongly with established cultural imagery. It has an accessible persuasiveness that makes it memorable as a heuristic and useful as a reminder. Secondly, there is a danger in appealing to established prejudices. If used unreflexively and inappropriately, the iceberg metaphor can end up reinforcing overly-static, reified and narrowly managerial and systemic views of an organization. Its critics are correct in this observation. However, there is nothing to prevent the generative employment of the iceberg 
metaphor. Our argument is for its use as 'counter-discourse' that opens up and creates discursive space, as people and ideas previously silenced are provided with vehicles and opportunities to speak up and 'talk back' (Moussa and Scapp, 1996). As a 'practical theory' this involves the use of the iceberg metaphor to counter the dominant reflex gut-feel overlyrational response to events in our thoughts and actions. Thirdly, the iceberg metaphor can, somewhat ironically, be productively used in conjunction with fluid imagery. Arguments for alternative fluid images may be made without reflection on their own partiality, ignore the role of rhetoric and drama in making an 'evidence-based' case for its superiority and relapse into or subordinate itself to a traditional rationalistic imperative to be agile and adaptive to align with a turbulent environment. The iceberg metaphor can act as a useful heuristic and ongoing reminder about the ingrained habits and institutional expectations that make such uses both likely and problematic. In addition, the iceberg metaphor can be elaborated in a more fluid manner and be reflectively self-critical about its potential blindness to fluidity and process. Geologists, historians, novelists and poets have pointed to the process of iceberg formation, travel and melting, the teeming of life within the iceberg and its ever-changing and productive character, the adoption of the iceberg's 'point of view' rather than those who fear colliding with it, and the changing views of the iceberg over time as a result of shifting trade routes and contemporary climate change. All of these can be used to elaborate the metaphor in different ways. At the same time, once the iceberg metaphor has opened up the importance of going below the surface and challenging the rational tip, it is possible to move into a generative discussion about what metaphors, images and metrics might be used to capture the phenomenon that the iceberg points to. This includes the added value of a variety of fluid images, contrasts between shadow and legitimate organizations, frontstage and backstage performances, organizations as domination, warfare or theatre etc. Pointing to the 
partial nature of the iceberg's generative content can be part of a generative process for its use.

In developing upon these points and arguing for the iceberg as a generative countermetaphor, this chapter makes the case for its use in opening up creativity and imagination rather than replacing one dogmatic viewpoint by another. As a counter-trope, narrative or discourse, the aim is to contribute to Weick's (2007: 15) version of a desirable educational agenda for managers. As Karl Weick put it, "To drop the tools of rationality is to gain access to lightness ... Knowledge involves acquiring. Wisdom involves dropping. Sensitivity to that difference is part of what I think it means to reconfigure management education”.

\section{References}

Alexander, J. (2013). The Dark Side of Modernity. Cambridge: Polity Press.

Alvesson, M., and Spicer, A. (2016). The Stupidity Paradox. London: Profile Books.

Alvesson, M., and Sveningsson, S. (2016). Changing organizational culture. The Journal of long term care administration (Vol. 22). New York: Routledge.

Ariely, D. (2009). Predictable Irrationality: The Hidden Forces that Shape our Decisions.

New York: Harper-Collins.

Aronson, E. (1989). The Rationalizing Animal. In H. Leavitt, L. Pondy, and D. Boje (Eds.), Readings in Managerial Psychology (pp. 134-144). Chicago and London: University of Chicago Press.

Badham, R. (2013). Short Change: An Introduction to Managing Change. Suny: Business Perspectives.

Badham, R. J. (2017). Reflections on the Paradoxes of Modernity: A Conversation with James March. The Oxford Handbook of Organizational Paradox. Oxford: Oxford University Press. 
Badham, R., and King, E. (2020). Mindfulness at Work: A Critical Review. Organization, 130

Barley, S. R., and Kunda, G. (2010). Design and Devotion : Surges of Rational and Normative Ideologies of Control in Managerial Discourse Gideon Kunda. Adminisrative Science Quarterly, 37(3), 363-399.

Barrett, F. J., and Cooperrider, D. L. (1990). Generative Metaphor Intervention: A New Approach for Working with Systems Divided by Conflict and Caught in Defensive Perception. The Journal of Applied Behavioral Science, 26(2), 219-239.

Bennett, M. J. (2013a). Culture is not like an iceberg. Retrieved January 28, 2020, from https://www.idrinstitute.org/2013/05/06/culture-not-like-iceberg/

Bennett, M. J. (2013b). The Ravages of Reification: Considering the Iceberg and Cultural Intelligence, Towards De-reifyhing Intercultural Competence. In File IV, Colle Val D'Elsa,. https://doi.org/10.1017/CBO9781107415324.004

Black, M. (1993). More about Metaphor. In A. Ortony (Ed.), Metaphor and Thought (pp. 1934). Cambridge: Cambridge University Press.

Boltanski, L. and Thevenot, L. (2006). On justification: Economies of worth.Princetone: Princeton University Press

Brighton, D. (2015). Destroy the Iceberg. Retrieved January 31, 2020, from https://brightonleadership.com/2015/10/06/destroy-the-iceberg/

Brunsson, N. (2014). Nils Brunsson (1985), The Irrational Organization: Irrationality as the Basis for Organizational Action and Change.M@n@gement, 2, 141-144.

Buchanan, D., and Badham, R. (2020). Power, Politics and Organizational Change (Third). London: Sage.

Buchanan, D., and Huczynski, A. (2019). Organizational Behaviour. London and New York: Pearson. 
Burke, K. (1935). Permanence_and_Change. New York: New Republic.

Burnes, B. (2017). Managing change. Harlow: Pearson Education.

Burns, T. (1961). Micropolitics : Mechanisms of Institutional Change. Administrative Science Quarterlyrative Science Quarterly, 6(3), 257-281.

Cavana, B., Goodman, M., and Maani, K. (2018). Personal Communication.

Chia, R., and Holt, R. (2008). The nature of knowledge in business schools. Academy of Management Learning and Education, 7(4), 471-486.

Childs, P. (2008). Modernism (2nd ed.). London: Routledge.

Clegg, S., Kornberger, M., Pitsis, T., and Mount, M. (2019). Managing and Organizations: An Introduction to Theory and Practice (Fifth). Thousand Oaks and London: Sage.

Cohen, M. D., March, J. G., and Olsen, J. F. (1972). A Garbage Can Model of Organizational Choice. Administrative Science Quarterly, 17(1), 1-25.

Collier, A. (2013). Culture is not like an iceberg. Retrieved July 30, 2018, from https://www.idrinstitute.org/2013/05/06/culture-not-like-iceberg/

Colville, I., Brown, A. D., and Pye, A. (2012). Simplexity: Sensemaking, organizing and storytelling for our time. Human Relations, 65(1), 5-15.

Cornelissen, J. P., Oswick, C., Christensen, L. T., and Phillips, N. (2008). Metaphor in organizational research: context, modalities and implications for research - Introduction. Organization Studies, 29(1), 7-22.

Cummings, S., Bridgman, T., and Brown, K. (2016). Unfreezing change as three steps. Human Relations, 69(1): 33-60.

Cummins, J. (2001). Negotiating Identities. San Francisco: Californian Association for Bilingual Education.

Cunliff, E. D. (2008). Connecting Systems Thinking and Action. The Systems Thinker, 15(2), $1-13$. 
Cunliff, E., and Monat, J. (2018). Personal Communication.

Dalton, M. (2017). Men Who Manage. (2nd ed.). London and New York: Routledge.

Edelman, L., and Talesh, S. (2011). To comply or not yo comply, that isn't the question: how organizations cunstruct the meaning of compliance. In C. Parker and V. Neilsen (Eds.), Explaining Compliance - (pp. 103-122). Cherltenham: Edward Elgar.

Es, R. van. (2011). Diagnosing Change. Deventer, Netherlands: Vakmedianet.

Eubanks, P. (2000). A War of Words in the Discourse of Trade. Carbondale and Edwardsville: Souther Illinois University Press.

Flyvbjerg, B. (2001). Making Social Science Happen. Cambridge: Cambridge University Press.

French, W., and Bell, C. (1973). Organization Development: Behavioral science interventions for organization develpment. Englewood Cliffs, NJ: Prentice Hall.

Gabriel, Y. (2016). Narrative ecologies and the role of counter-narratives. In S. Frandsen, T. Kuhn, and M. Lundholt (Eds.), Counter_Narratives and Organization (pp. 208-226). London: Routledge.

George, A. (2018). Kenneth Burke's Permanance and Change: A Critical Companion. Columbia, South Carolina: University of South Carolina Press.

Giorgi, S., Lockwood, C., and Glynn, M. A. (2015). The Many Faces of Culture: Making Sense of 30 Years of Research on Culture in Organization Studies. Academy of Management Annals, 9(1), 1-54.

Green, C. (2019). Where did Freud's iceberg metaphor of mind come from? History of Psychology (Vol. 22).

Gusfield, J. R. (2000). Performing Action. Performing Action. New Brunswick and London: Transaction.

Hall, E. T. (1959). The Silent Language. New York: Doubleday. 
Hall, E. T. (1966). The Hidden Dimension. New York: Doubleday. https://doi.org/10.2307/1572461

Hall, E. T. (1976). Beyond Culture. New York and London: Doubleday.

Hatch, M. (2013). Organization theory: Modern, symbolic and post-modern perspectives. Oxford: Oxford University Press.

Hayes, J. (2020). The Theory and Practice of Managing Change. London: Red Globe.

Hellriegel, D., and Slocum, J. (2011). Organizational Behavior (13th ed.). Mason, Ohio: Cengage Learning.

Hellriegel, D, Slocum, J. and Woodman. R. (1998). Management. Nashville: South-Western Publishing.

Herman, S. (1971). What is this Thing Called Organization Development? Personnel Journal, (August), 595-603.

Herman, S. (2018). Personal Communication.

Hitchins, D. (2018). Personal communication via Jamie Monat.

Hochschild, A. R. (1983). The Managed Heart: Commercialization of Human Feeling. Berkeley: University of California Press.

Hughes, M. (2019). Managing and Leading Change. London: Taylor and Francis.

Jacobs, C. D., and Heracleous, L. T. (2006). Constructing shared understanding: The role of embodied metaphors in organization development. Journal of Applied Behavioral Science, 42(2), 207-226.

Jagd, S. (2011). Pragmatic sociology and competing orders of worth in organizations. European Journal of Social Theory, 14(3), 343-359.

Kanter, R. M., Stein, B. A., and Jick, T. D. (1992). The challenge of organizational change: How companies experience it and leaders guide it. New York: Free Press.

Kim, D. (1999). Introduction to Systems Theory. New York: Pegasus Communications. 
Knights, D., and Willmott, H. (2006). Introducing Organizational Behaviour and Management. London and New York: Thomson Learning.

Kunda, G. (2006). Engineering Culture: Control and Commitment in a High-Tech Corporation. Philadelphia: Temple University Press.

Lakoff, G., and Turner, M. (1989). More than Cool Reason: A Field Guide to Poetic Metaphor. Chicago and London: University of Chicago Press. Retrieved from

Maclean, M., Harvey, C. and Stringfellow, L.J. (2017). Narrative, metaphor and the subjective understanding of historic identity transition. Business History, 59(8), 12181241.

Mccabe, D. (2016). ' Curiouser and curiouser!': Organizations as Wonderland - a metaphorical alternative to the rational model. Human Relations, 69(4), 945-973.

Maccoby, M. (1978). The Gamesman: Winning and Losing the Career Game. New York: Bantam

MacQueen, J. (2020). The Flow of Organizational Culture New Thinking and Theory for Better Understanding and Process. London: Palgrave Macmillan.

March, J. (2007). Management and Don Quixote. HEC Paris France: YouTube. Retrieved from https://www.youtube.com/watch?v=bztgYMoTEjM

March, J. G. (1992). The war is over and the victors have lost. Journal of Socio-Economics, 21(3), 261-267.

March, J. G. (2007). Management and Don Quixote. France: HEC, You Tube.

Marshak, R. J. (1993). Managing the Metaphors ofChange. Organizational Dynamics, 22(1), $44-56$.

Mendelsohn, B. D. (2012). UNSINKABLE: Why we can't let go of the Titanic, 1-16. Retrieved from http://www.newyorker.com/magazine/2012/04/16/unsinkable-3

Meyer, J. W., and Rowan, B. (1977). Institutionalized Organizations : Formal Structure as 
Myth and Ceremony. American Journal of Sociology, 83(2), 340-363.

Monat, J. P., and Gannon, T. F. (2015). What is Systems Thinking? A Review of Selected Literature Plus Recommendations. American Journal of Systems Science, 4(1), 11-26. Morgan, G. (1989). Creative Organization Theory. Newbury Park: Sage.

Morgan, G. (2006). Images of Organization. London: Sage.

Moussa, M., and Scapp, R. (1996). The Practical Theorizing of Michel Foucault : Politics and Counter-Discourse. Cultural Critique, 33(Spring), 87-112.

Mueller, C. (2008). Metaphors Dead and Alive, Sleeping and Waking: A Dynamic View. Chicago and London: University of Chicago Press.

Mullins, L., and Christy, G. (2010). Management and Organizational behaviour. London and New York: Pearson.

Oswick, C., Keenoy, T., and Grant, D. (2002). Metaphor and Analogical Reasoning in Organization Theory: beyond Orthodoxy. The Academy of Management Review, 27(2), 294.

Palmer, I., and Dunford, R. (1996). Conflicting uses of metaphors: Reconceptualizing their use in the field of organizational change. Academy of Management Review, 21(3), 691717.

Pettigrew, A. M. (1979). On Studying Organizational Cultures. Administrative Science Quarterly, 24(4), 570.

Reynolds, M., and Vince, R. (2016). Organizing Reflection. Abingdon and New York: Routledge.

Rick, T. (2014). Organizational Culture is Like an Iceberg. Retrieved January 19, 2020, from http://www.torbenrick.eu/blog/culture/organizational-culture-is-like-an-iceberg/

Rick, T. (2015). The Iceberg that Sinks Organizational Change. Retrieved January 19, 2020, from https://www.torbenrick.eu/blog/change-management/iceberg-that-sinks- 
organizational-change/

Rowan, B. (2002). Rationality and reality in organizational management: Using the coupling metaphor to understand educational (and other) organizations - a concluding comment. Journal of Educational Administration, 40(6), 604-611.

Scharmer, O., and Kaufer, K. (2013). Leading from the Emerging Future. San Francisco: Berrett-Koehler.

Schein, E. (2020). Personal Communication.

Schein, E. H., and Schein, P. (2019). The Corporate Culture Survival Guide. The Corporate Culture Survival Guide. Hoboken and San Francisco: Wiley.

Schon, D. (1979). Displacement of Concepts. London: tavistock.

Schwartz, B., and Sharpe, K. (2011). Practical Wisdom: The Right Way to Do the Right Thing. New York: Riverhead Books.

Scott, J. (1999). Seeing Like a State. New Haven: Yale University Press.

Senior, B., and Fleming, J. (2006). Organizational Change. London: Prentice Hall.

Senior, B., and Swailes, S. (2016). Organizational Change (5th ed.). Harlow: Pearson Education.

Sillince, J. A. A., and Golant, B. D. (2017). The Role of Irony and Metaphor in Working through Paradox during Organizational Change.

Steinitz, J. (2015). What 's metaphor got to do with it? Troping and counter-troping in Holocaust victim language. University of Iowa. Retrieved from http://ir.uiowa.edu/etd/1910.

Stouten, J., Rousseau, D. M., and De Cremer, D. (2018). Successful Organizational Change: Integrating the Management Practice and Scholarly Literatures. Academy of Management Annals, 12(2), 752-788.

Sun, L., Paez, O., Lee, D., Salem, S., and Daraiseh, N. M. (2006). Estimating the uninsured 
costs of work-related accidents, part I: A systematic review. Theoretical Issues in Ergonomics Science, 7(3), 227-245.

Swuste, P. (2018). Personal communcation.

Swuste, P., Gulijk, C. Van, and Zwaard, W. (2010). Safety metaphors and theories , a review of the occupational safety literature of the US, UK and The Netherlands, till the first part of the 20th century. Safety Science, 48, 1000-1018.

Taylor, C. (2004). Modern Social Imaginaries. Rocky Mountain Review of Language and Literature (Vol. 60). Durham and London: Duke University.

Underhill, J. (2012). Ethnolinguistics and Cultural Concepts. Cambridge and New York: Cambridge University Press.

Vaill, P. (1989). Managing as a Performing Art. San Francisco: Jossey-Bass.

Weick, K. (1979). The Social Psychology of Organizing. Read: Addison-Wesley.

Weick, K. E. (2007). Drop your Tools: On Reconfiguring Management Education. Journal of Management Education, 31(5), 5-16

Wessel, L. (2018). The base of the iceberg: It's big and teeming with life. Knowable Magazine, 20-21.

Westwood, R. and Clegg, S. (Eds.) 2003). Debating organization: Point-counterpoint in organization studies. Oxford: Blackwell.

Whyte, W.H. (1956) The Organization Man. New York: Simon and Schuster.

Wilson, J. (2015). Political Discourse. In D. Tannen, H. Hamilton, and D. Schiffrin (Eds.), Handbook of Discourse Analysis (pp. 775-795). Chichester: Wiley-Blackwell 